\title{
Synthesis and Some Properties of Polyurethane Cationomers with Side Chain Azoaromatic Chromophores
}

\author{
Emil C. Buruiană, Tinca Buruiană, Anton Airinei, Gabriela Robilă, \\ and Irinel GRECU* \\ Institute of Macromolecular Chemistry "P. Poni," \\ Aleea Gr. Ghica Vodă 41 A, 6600 Iași, Romania \\ *Department of Physics, Technical University "Gh. Asachi”, Iași, Romania
}

(Received October 15, 1998)

\begin{abstract}
New polyurethane cationomers bearing side chain azoaromatic chromophores on non-ionic fragment of hard segments were synthesized and characterized. Their photobehavior in solutions and polymeric films was investigated by electronic absorption spectroscopy and was evaluated comparatively with a non-ionic azourethane model and polyurethane precursor. Under UV irradiation only the polymer solutions showed a typical photochromism, while in film state, the reversible process was impeded even at higher temperatures. By exposure at iodine vapors for $1-2 \mathrm{~min}$, the cis-trans isomerization in irradiated polymer films is possible too.

KEY WORDS Azo Polyurethane/Cationomers / Photochromic Behavior /
\end{abstract}

In the last few years, among the polymeric materials bearing a variety of chromophores, the polyurethanes have attracted much attention owing to the possibility of tailoring of the properties by a convenient choice of reaction partners. ${ }^{1,2}$ Many reports have been oriented to the development of polyurethanes containing azoaromatic moieties as side groups or in the main chain, with emphasis on the obtaining of the photochromic, liquid-crystal, nonlinear optical or biological properties. $^{3-6}$ On the other hand, such studies provided information on the mobility of the host polymer chains and the physical aging at molecular level. ${ }^{7,8}$

Our attention has turned to polyurethane ionomers which contain a minority of ionic groups (usually $1 \mathrm{meq}^{-1}$ or less) ${ }^{9}$ recognized for their unique properties with applications in the field of coatings and adhesives. ${ }^{10,11}$ By incorporation of different chromophores in ionomeric polyurethanes could result in an enhanced knowledge of their features, opening the way to design new materials for optical devices.

In the previous papers, ${ }^{12-16}$ series of polyurethane ionomers with azoaromatic or/and nitroaromatic units covalently or electrostatically bound to the hard segments of the polymer chains were synthesized and studied with respect to some of their photophysical properties. Investigation of such polymers has evidenced structural changes that take place during the UV irradiation and has established that the photoprocess evolution is a function of nature and content of chromophore attached on polymer chain.

Based on the results concerning photobehavior of polyurethane cationomers with azoaromatic groups attached to quaternary nitrogen atoms, ${ }^{12,16}$ it is interesting to introduce the azo functionality in non-ionic fragment of hard segments, to follow the influence of ionic structure on the photochromic properties of the corresponding polycation. Synthesis and some properties of chromophoric cationomers containing such azoaromatic units, comparatively with non-ionic azourethane model and polyurethane precursor will be reported here.

\section{EXPERIMENTAL}

\section{Materials}

Poly(tetramethylene oxide) diol (PTMO, $M_{n}=2000$, Aldrich Chem. Comp.) was dried and degassed at 100$110^{\circ} \mathrm{C}$ and $1-2 \mathrm{mmHg}$ for $2 \mathrm{~h}$ before utilization. $4,4^{\prime}$ Dibenzyldiisocyanate $\left(4,4^{\prime}\right.$-DBDI) was synthesized in our laboratory ${ }^{17}$ and freshly distilled before use. $N$ Methyldiethanolamine (NMDA, Aldrich Chem. Comp.) was used as received. Dimethylformamide (DMF) and the solvents used in the synthesis were dried over $5 \AA$ molecular sieves.

\section{Monomer Synthesis: 4-N,N-di( $\beta$-hydroxyethyl $)$ aminoazo- benzene $(A z-D)$}

Aniline $(0.1 \mathrm{~mL})$ was added in $\mathrm{H}_{2} \mathrm{O}(20 \mathrm{~mL})$ and aqueous $\mathrm{HCl}(20 \mathrm{~mL}, 37 \%)$ and then an aqueous solution of sodium nitrite $(0.1 \mathrm{~mol}, 30 \mathrm{~mL})$ was dropped at $5^{\circ} \mathrm{C}$. The resulting diazonium salt was coupled with $N, N$ $\operatorname{di}(\beta$-hydroxyethyl)aniline $(0.01 \mathrm{~mol})$ dissolved in glacial acetic acid $(20 \mathrm{~mL})$ at $2-4^{\circ} \mathrm{C}$ for $40 \mathrm{~min}$. In the obtained mixture sodium acetate $(0.1 \mathrm{~mol})$ was added and the temperature of reaction was kept at $2-4^{\circ} \mathrm{C}$ for $60 \mathrm{~min}$. The ice-water bath was then removed and stirring was continued at room temperature, when the solution was neutralized with $\mathrm{NaOH}$ at $\mathrm{pH} 3-4$. The solid product obtained was filtered, dissolved in tetrahydrofuran (THF) and then precipitated in water. The azo-diol was isolated by filtration and recrystallization from $\mathrm{C}_{2} \mathrm{H}_{5} \mathrm{OH}: \mathrm{H}_{2} \mathrm{O}$ $(1: 3 \mathrm{v} / \mathrm{v})$. Yield: $25 \mathrm{~g}(87.4 \%)$.

${ }^{1} \mathrm{H}$ NMR [(dimethyl sulfoxide- $\left.d_{6}\right)\left(\right.$ DMSO- $\left.\left.d_{6}\right)\right], \delta$ (ppm): $7.75(4 \mathrm{H}, \mathrm{d}$, aromatic protons ortho to $\mathrm{N}=\mathrm{N})$; $7.25(3 \mathrm{H}, \mathrm{m}$, aromatic protons meta and para $) ; 6.75(2 \mathrm{H}$, $\mathrm{d}$, aromatic protons ortho to $\left.\mathrm{N}-\mathrm{CH}_{2}\right) ; 3.75(4 \mathrm{H}, \mathrm{m}$, $\left.\mathrm{HO}-\mathrm{CH}_{2}\right) ; 3.55\left(4 \mathrm{H}, \mathrm{t},-\mathrm{N}-\mathrm{CH}_{2}\right)$

IR $(\mathrm{KBr}): v\left(\mathrm{~cm}^{-1}\right)=3450(\mathrm{OH}), 2900-2950(\mathrm{C}-\mathrm{H})$, $1600(\mathrm{C}-\mathrm{H}$ aromatic), 1370 and $1150(\mathrm{~N}=\mathrm{N}), 820$ $\left(1,4-\mathrm{C}_{6} \mathrm{H}_{4}\right)$.

Model Synthesis: Azo-Urethane Model (Az-M)

Az-D (10 mmol, $2.85 \mathrm{~g})$ was dissolved in anhydrous 
DMF $(20 \mathrm{~mL})$ and phenyl isocyanate $(20 \mathrm{mmol}, 2.38 \mathrm{~g})$ was added dropwise. The reaction mixture was stirred at $55^{\circ} \mathrm{C}$ for $6 \mathrm{~h}$. After removing DMF at low pressure, the solid product was recrystallized from acetonitrile. The reaction quantitatively occurred. Yield: $5.18 \mathrm{~g}(99 \%)$.

${ }^{1} \mathrm{H}$ NMR (DMSO- $\left.d_{6}\right), \delta(\mathrm{ppm}): 7.0(4 \mathrm{H}, \mathrm{d}$, aromatic protons ortho to $\mathrm{NHCOO}) ; 7.5(6 \mathrm{H}, \mathrm{m}$, aromatic protons meta and para to NHCOO); 8.25 (2H, m, NHCOO); 7.75 $(4 \mathrm{H}, \mathrm{d}$, aromatic protons ortho to $\mathrm{N}=\mathrm{N}) ; 7.25(3 \mathrm{H}, \mathrm{m}$, aromatic protons meta and para $) ; 6.75(2 \mathrm{H}, \mathrm{d}$, aromatic protons ortho to $\left.\mathrm{N}-\mathrm{CH}_{2}\right) ; 3.55\left(4 \mathrm{H}, \mathrm{t}, \mathrm{CH}_{2}-\mathrm{N}\right) ; 4.25$ $\left(4 \mathrm{H}, \mathrm{t}, \mathrm{CH}_{2}-\mathrm{OCONH}\right)$.

IR $(\mathrm{KBr}): v\left(\mathrm{~cm}^{-1}\right)=3300$ (hydrogen-bonded $\mathrm{N}-\mathrm{H}$ stretching), 3430 (not hydrogen-bonded N-H stretching vibration), 1730 (not hydrogen-bonded $\mathrm{C}=\mathrm{O}$ stretching vibration), 1710 (hydrogen-bonded $\mathrm{C}=\mathrm{O}$ stretching vibration $), 2900-2950(\mathrm{C}-\mathrm{H}), 1600(\mathrm{C}-\mathrm{H}$ aromatic $)$, 1370 and $1150(\mathrm{~N}=\mathrm{N}), 820\left(1,4-\mathrm{C}_{6} \mathrm{H}_{4}\right), 770\left(\mathrm{C}_{6} \mathrm{H}_{5}\right)$.

\section{Polymer Synthesis}

Cationic polyurethanes were synthesized by the "prepolymer" method under purified nitrogen. Dry PTMO $(0.01 \mathrm{~mol})$ reacted with $4,4^{\prime}$-DBDI $(0.03 \mathrm{~mol}$ for PUC-1 or $0.02 \mathrm{~mol}$ for PUC-2) at $50-55^{\circ} \mathrm{C}$ for $5-6 \mathrm{~h}$. The diol mixture (1:1 molar ratio), NMDA and Az-D (0.02 mol for PUC-1 or 0.01 mol for PUC-2), dissolved in dry DMF, was added to the prepolymer and the reaction was continued in DMF solution $\left(c=10 \mathrm{~g} \mathrm{dL}^{-1}\right)$ at the same temperature still $4-5 \mathrm{~h}$. By adding benzyl chloride $(0.01 \mathrm{~mol}$ or $0.005 \mathrm{~mol})$ at $50-55^{\circ} \mathrm{C}$ for $4-5 \mathrm{~h}$ the quaternization reaction occurred. All the polymers were precipitated with ethyl ether and then dried under reduced pressure at $55-60^{\circ} \mathrm{C}$ for $48 \mathrm{~h}$.

\section{Measurements}

The ionic chlorine was determined titrimetrically. Reduced viscosity of precursors was measured at $25 \pm$ $0.2^{\circ} \mathrm{C}$ in DMF solution $\left(c=0.3 \mathrm{~g} \mathrm{dL}^{-1}\right)$ using an $\mathrm{Ub}$ belohde viscometer with $0 \mathrm{~A}$ capillary.

${ }^{1} \mathrm{H}$ NMR spectra were obtained on a JEOL C60HL spectrometer. Electronic absorption spectra were measured with a Specord M42 spectrophotometer in DMF solutions and films.

Irradiations were carried out using a $500 \mathrm{~W}$ high pressure mercury lamp at room temperature in $10 \mathrm{~mm}$ path length quartz cells fitted with PTFE stoppers. The initial absorbance of the samples under the study in the absorption band maximum was maintained between 0.9 and 1.0. The polymer films were deposited on quartz plates by casting from DMF solutions $\left(c=1 \mathrm{~g} \mathrm{dL}^{-1}\right)$ and then allowed to dry at $50-55^{\circ} \mathrm{C}$ under reduced pressure for $2-3$ days.

\section{RESULTS AND DISCUSSION}

\section{Synthesis of Polymers}

Synthesis of the segmented polyurethanes was performed by a polyaddition reaction between a typical oligomeric diol (PTMO), 4,4'-DBDI, and a diol mixture, namely azo-diol (Az-D) and NMDA (1:1 molar ratio), as chain extenders with chromophoric and potential cationic functionality. By using benzyl chloride as quaternization agent of aliphatic tertiary nitrogen atoms from aforementioned precursor, polyurethane cationomers containing quaternary groups as well as azoaromatic units, covalently bound to polymeric chains were prepared according to Scheme 1.

Depending on the choice of molar ratio between polyaddition partners $(1 / 3 / 2$ or $1 / 2 / 1)$, two cationomers (PUC-1, PUC-2) with different concentration of ionic and azoaromatic groups, respectively, were synthesized and undertaken in our study (Table I). Incorporation of azoaromatic moieties by means of chain co-extender in the hard segments of ionic polyurethanes could be an effective tool for evaluation of the role played by the point of attachement to the non-ionic segment of polymer backbone as well as its effect on the evolution of photoisomerization process. Solutions from these red polymers, as resulted from reaction, were coated onto a glass substrate and dried to yield colored, flexible, and optical quality polymeric films, which exhibit typical elastomeric characteristics of the conventional polyurethanes. All polymers dissolved in polar solvents, such as DMF, DMA, and DMSO. The relative high value of the reduced viscosity of precursors ( $\eta_{\text {red }}$ : $0.38 \mathrm{dL} \mathrm{g}^{-1}$ for PR-1 and $0.41 \mathrm{dL} \mathrm{g}^{-1}$ for PR-2), assumes the high molecular nature of these polymers and their film forming ability at ambient temperature. Moreover, the functional properties of resulting cationomers are mainly derived from the existence of small amount of quaternary groups associated in ionic aggregations, which can also influence the dynamic of photoprocess.

\section{Photo- and Thermal Isomerization of Model Compound}

Evaluation of photobehavior of the synthesized polymers represents the most important objective of this study. Given the various aspects of the photobehavior of many azoaromatic moieties from the polymeric chains intended for optical applications, it is interesting to compare the photosensitive properties of the above cationomers with corresponding non-ionic precursor (PR-1) and an azo urethane model (Az-M).

Normally, azoaromatic groups are in the thermodinamically more stable trans configuration. Photoexcitation of this structure, achieved with a high pressure $\mathrm{Hg}$ lamp, induces a structural change of trans conformer to the cis form. Once the molecule is in the cis form, it recovers to the initial trans form by either the back thermal reaction or the inverse photoisomerization cycle.

In our experiment, the trans-cis photoisomerization of azourethane model in DMF, can be seen from the spectral changes under different exposure time, as shown in Figure 1. Upon UV irradiation is evident that the intensity of absorption band centered at $423.5 \mathrm{~nm}$ and assigned to $\pi-\pi^{*}$ transition of trans isomer, decreased progressively over time, reaching a relative photostationary state by only $60 \mathrm{~s}$. In this case, the trans-cis photoisomerization is a fast reaction in dilute solution, leading to a molar fraction of cis isomer of 0.47 in the photostationary state, characterized by two absorption maxima at $381 \mathrm{~nm}$ and $429 \mathrm{~nm}$. In the same time, during UV irradiation of Az-M a bathocromic shift of absorption maximum from $423.5 \mathrm{~nm}$ as well as the formation of a new band (shoulder) at $381 \mathrm{~nm}$, even in the first stages of the photoreaction were observed, too. 
E. C. BURUiAnă et al.

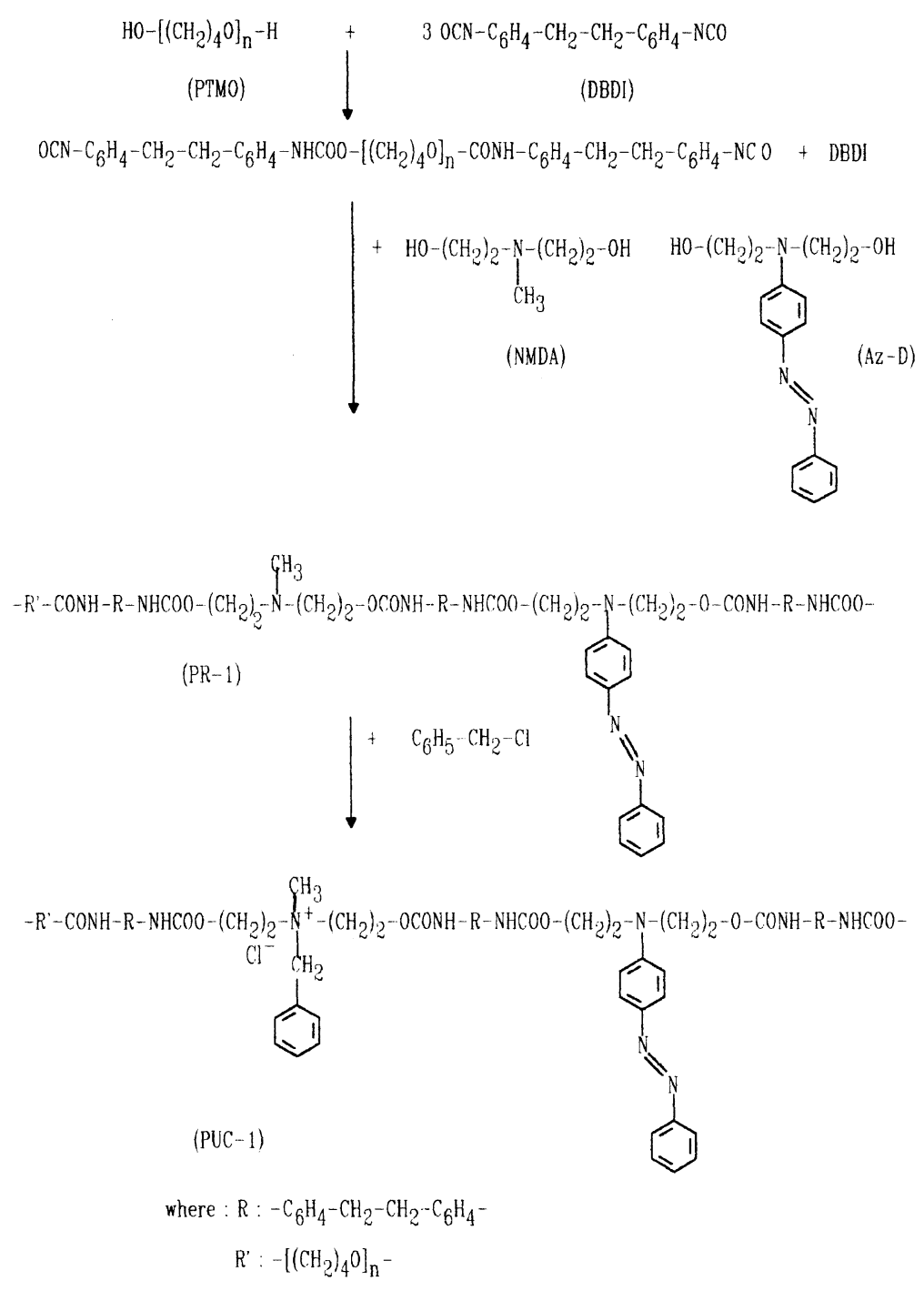

Scheme 1.

Table I. Structural characteristics of polyurethane cationomers

\begin{tabular}{|c|c|c|c|c|}
\hline \multirow{2}{*}{ Sample } & \multirow{2}{*}{$\begin{array}{c}\text { Ionic chlorine } \\
\text { content } \\
\text { (meq/100g) }\end{array}$} & \multicolumn{2}{|c|}{$\lambda_{\max } / \mathrm{nm}$} & \multirow{2}{*}{$\frac{k \times 10^{5}}{\mathrm{~s}^{-1}}$} \\
\hline & & DMF & Film & \\
\hline PUC-1 & 28.56 & 415.0 & 412.5 & 11.9 \\
\hline PUC-2 & 16.42 & 408.0 & 406.0 & - \\
\hline PR-1 & - & 415.5 & 410.0 & 17.7 \\
\hline Az-M & - & 423.5 & - & 98.8 \\
\hline
\end{tabular}

The appearance of this new absorption band could be attributed to cis configuration of aminoazobenzene moieties. The presence of two isosbestic points at $381.5 \mathrm{~nm}$ and $501 \mathrm{~nm}$ suggested that the photoisomerization is only photochemical change of this chromophore type and no side reactions, as photodegradation, are involved.

The kinetics of cis-trans relaxation process of azochromophores in Az-M was followed by monitoring the changes of absorbance at $429 \mathrm{~nm}$, either by the recovery at room temperature in dark or by irradiation with $365 \mathrm{~nm}$ light, in the new absorption band. In the both cases, the return to the initial trans configuration state occurred, but with different rates. Thus, the thermal

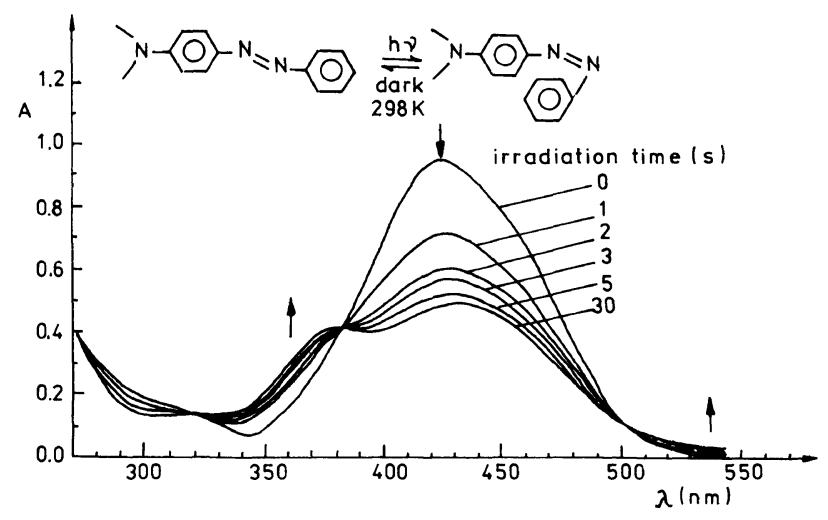

Figure 1. Changes in electronic absorption spectra of azo model $(\mathrm{Az}-\mathrm{M})$ in DMF solution during UV irradiation at $298 \mathrm{~K}$. The irradiation times are indicated in figure.

cis-trans isomerization takes place in 100 min by standing in dark, while the same process achieved by irradiation with $365 \mathrm{~nm}$ light is much rapidly, especially in the first stage of the photoreaction. A such behavior evidences photochromic nature of azochromophore from this nonionic model, in contrast to that found in other model containing azoaromatic groups attached to quaternary nitrogen. ${ }^{12}$ The probable explanation of this result 


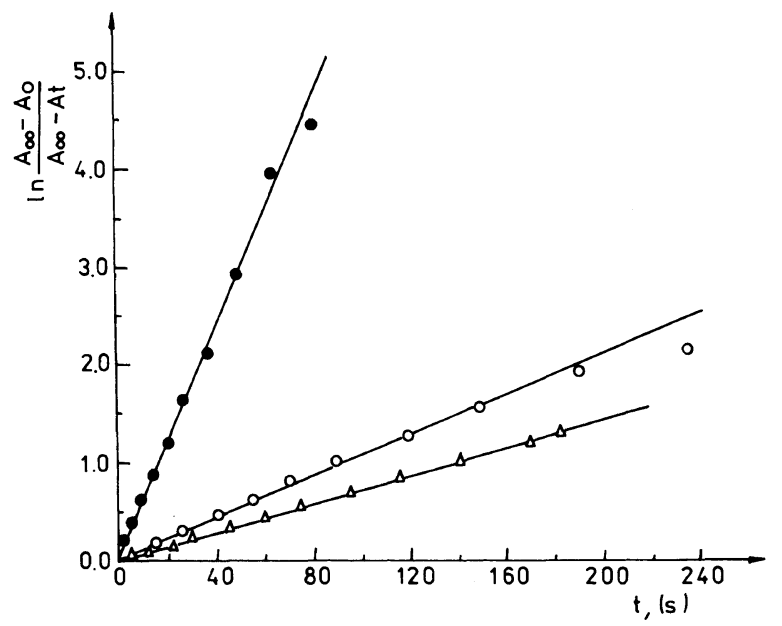

Figure 2. First-order plots for the thermal cis-trans isomerization of azo chromophores in DMF at $298 \mathrm{~K}$ : Az-M ( ), PR-1 (O), and PUC-1 $(\triangle)$.

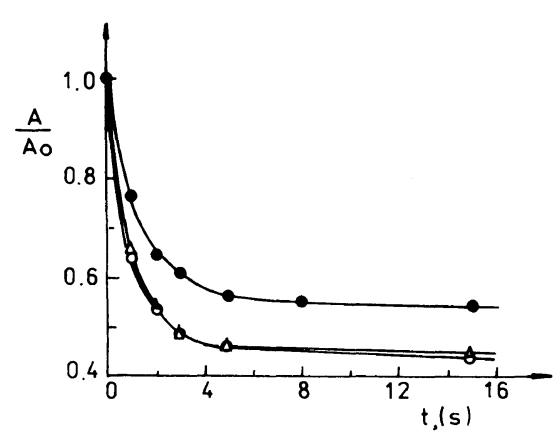

Figure 3. Decrease of relative absorbance $\left(A / A_{0}\right)$ as a function of irradiation time for trans cis photoisomerization in DMF solution at $298 \mathrm{~K}:$ Az-M (O), PR-1 (○), and PUC-1 $(\triangle)$.

could be related to the different effects of restriction on the mobility of the azoaromatic moiety owing to its attachment point to hard segment of ionic or non-ionic type.

The thermal cis-trans isomerization can be expressed by a first order rate equation ${ }^{18}: \ln \left(A_{\infty}-A_{0}\right) /$ $\left(A_{\infty}-A_{t}\right)=k t$, where $A_{0}, A_{\infty}$, and $A_{t}$ are values of the absorbance at times $t_{0}, t_{\infty}$, and $t$, respectively and $k$ is the rate constant of cis-trans isomerization. The first order plot for thermal cis-trans isomerization of the azoaromatic chromophore in DMF solution of Az-M is shown in Figure 2.

\section{Photo- and Thermal Isomerization of Polymers}

To examine the influence of hindered motions of the azochromophores during UV irradiation, the kinetics of photochemical trans to cis and cis to trans back isomerization of azo groups in polymer solutions as well as film state was studied. Under the same irradiation conditions, the trans-cis photoisomerization of azoaromatic units in DMF solutions of PR-1 and PUC-1 exhibited a photobehavior quite similar to that observed for above described azo model (Figure 3). The time required for attaining photostationary state with a content of cis fraction of 0.55 , being $15 \mathrm{~s}$ (PR-1) and $30 \mathrm{~s}$ (PUC-1) respectively, was comparable with that found in the control experiment performed on model, but the rate of this process is different. Apparently, the

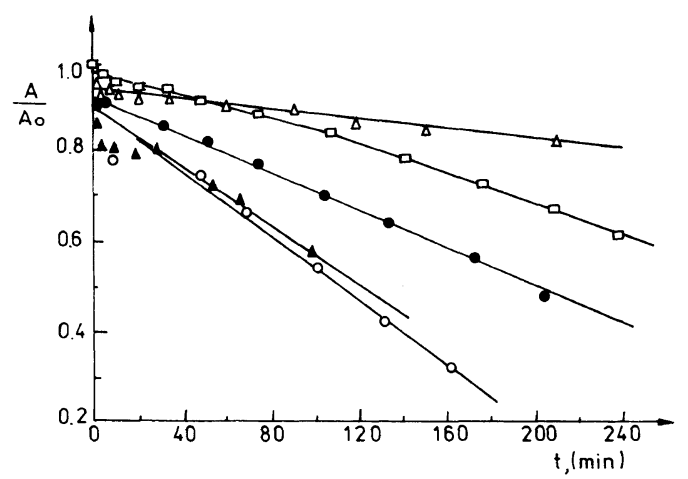

Figure 4. Dependence of relative absorbance on irradiation time of polyurethane films during UV irradiation at $298 \mathrm{~K}$ : PR-1 $(\triangle)$, PUC-1 $(\square)$ PUC-2 (O), PUC-2 with 1 wt $\%$ nitropolyurethane-PU-NO $\mathrm{N}_{2}(\mathbf{O})$, PUC-2 with 1 wt $\%$ benzophenone $(\boldsymbol{A})$.

differentiation between the photoresponse of model comparative with that of polymers is probably due to the higher rate of cis-trans photoisomerization in azo model accompanying the trans-cis photoreaction. Comparison of the photobehavior of non-ionic polyurethane with that of ionomer polyurethane shows that the presence of quaternary structure besides chromophore units retards slightly the attaining of photostationary state as a consequence of electrostatic interactions specifically to the ionic systems. Unlike the polyurethane ionomer bearing azoaromatic chromophore attached to quatternary nitrogen atoms, ${ }^{12}$ the above ionomer showed a significantly increased sensitivity to UV irradiation, suggesting a higher conformational mobility of the polymer chains with azoaromatic units as non-ionic fragments of the hard segments. It can be also remarked that the systematic shifts of the absorption maxima towards longer wavelengths for all chromophoric polymers, are apparently due to a microenvironmental polarity effect surrounding of the azoaromatic groups.

The thermal back isomerization of PR-1 and PUC-1 solutions in DMF was studied at room temperature and followed a first order kinetics in solution (Figure 2). The values of the rate constant that were estimated from the first order plots shown in Figure 2, are listed in Table I. The thermal isomerization is much slower for the two polymers by comparison with azo model, indicating the important role played by the polymer chains in controlling the rate of this chemical reaction in polar medium. One of the parameters that affects the rate of cis-trans isomerization is temperature. It was clearly observed that a strong enhancement of the thermal recovery in the both polymers occurring at higher temperature (recovery time at $90^{\circ} \mathrm{C}$ is about $7 \mathrm{~min}$ ).

In polymer films, as a consequence of a lower mobility of chromophore moieties, the trans-cis photoisomerization of azoaromatic groups was substantially slower than in solution. From the results shown in Figure 4 , it is clearly observed that this photoreaction requires much longer times of irradiation for reaching to an equilibrium state. Thus, the relative absorbance $A / A_{0}$ is 0.63 , after 240 min of irradiation for PUC-1 film, while in DMF solution of the same sample $A / A_{0}$ is 0.45 , after only ten seconds. As is shown in Figure 5, the first photoprocess is the photoisomerization of azo chromophores 


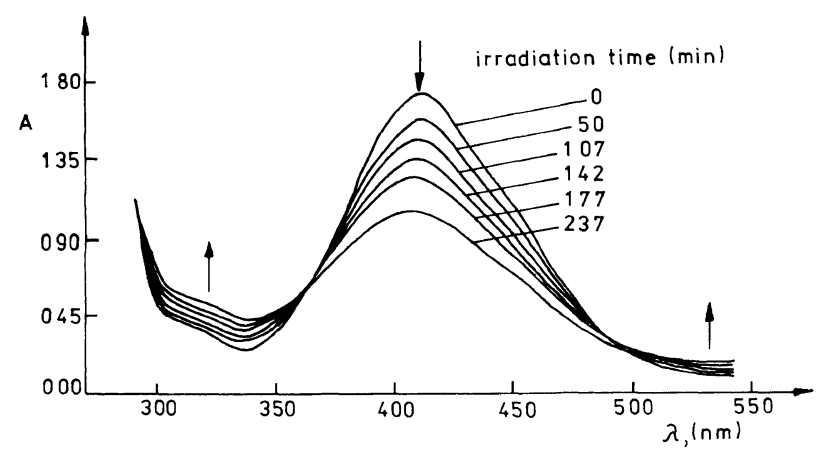

Figure 5. UV-VIS absorption spectra monitoring the photochemical transformation of azo chromophores in polyurethane film PUC-1 at $298 \mathrm{~K}$.

proved by the presence of two isosbestic points at 364 and $497 \mathrm{~nm}$, respectively. After $150 \mathrm{~min}$ of UV irradiation on PUC-1 film, the isosbestic points did not maintain in spectra and the photobleaching process starts in the polymer film. This latter photoprocess takes place very slowly as the reaction goes on. In the case of nonionic polyurethane (PR-1), the degree of transformation of the chromophore groups during the irradiation is very low (15\% after $210 \mathrm{~min}$ of UV irradiation). As seen, the rate of photobleaching process is higher in the case of ionomer film of PUC-1 (Figure 4) than that of non-ionomeric polymer. It is reasonable to assume that the longer times of irradiation affect the stability of the ammonium quaternary structures enhancing this photoprocess.

The changes in the electronic absorption spectra are much pronounced for film of PUC-2, with a smaller azoaromatic group content. In this case, the intensity of absorption band at $406 \mathrm{~nm}$ decreases much faster during irradiation (Figure 4), the fractions of cis isomer at irradiation time of $50 \mathrm{~min}$ are 0.24 (PUC-2) and 0.09 (PUC-1), respectively. A shoulder at $368 \mathrm{~nm}$ was formed in the first stages of the photoreaction and the isosbestic points are located at 367 and $476 \mathrm{~nm}$. During irradiation, the absorption band at $406 \mathrm{~nm}$ shifted to shorter wavelengths and the photobleaching is the second process of the photoreaction, when the isosbestic points do not exist in spectrum. The electronic absorption spectra of PUC-2 film exhibited no modification by standing at $120^{\circ} \mathrm{C}$ for $405 \mathrm{~min}$, the photobleaching process being irreversible in these conditions.

\section{Effect of Additives}

It seems possible to enhance the photostimulated activity of polymer chains by incorporation of some sensitizers in polymer films, such as iodine vapors, benzophenone or a nitropolyurethane. Following the evolution of the photoprocess (Figure 4) it was observed that the presence of benzophenone or nitropolyurethane $^{14}$ in PUC-2 films does not enhance the dynamics of photoprocess. The photoprocess rate in cationomer film containing nitropolyurethane was reduced as compared to PUC-2.

A somewhat different behavior was evidenced to the exposure of irradiated films at iodine vapors (for low exposure times of $1-2 \mathrm{~min}$ ), known as catalyst of cis-trans isomerization for azobenzene derivatives. In the

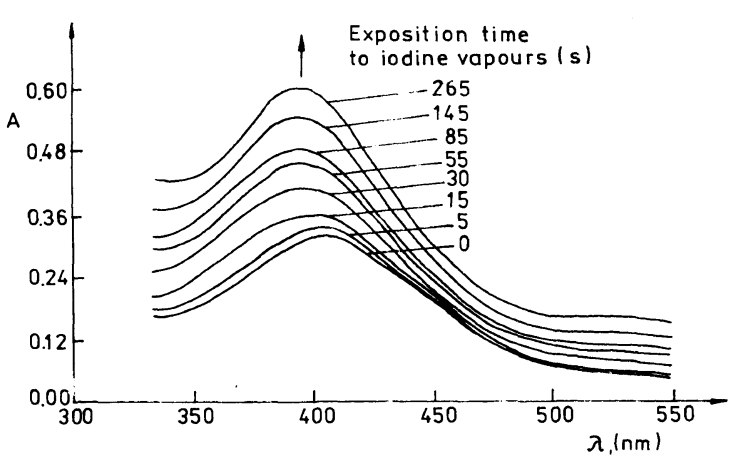

Figure 6. Influence of iodine vapors on the electronic spectra of UV irradiated thin polyurethane film PUC-2. The exposition times to iodine are given in figure.

Figure 6 is depicted the effect of iodine vapors on the behavior of PUC-2 film, irradiated $170 \mathrm{~min}$, when the ratio between $A / A_{0}$ is 0.54 . As can be seen from this figure, a fast increase of the absorbance at $405 \mathrm{~nm}$ was observed reaching almost the starting of initial absorbance value. In the same time, a polyurethane film based on PTMO, 4,4-DBDI, and NMDA (1:2:1 molar ratio), treated with iodine vapors exhibited an absorption band at $357 \mathrm{~nm}$, assigned to some complexes of iodine with aromatic structure. These results confirm that the cis-trans isomerization in PUC-2 film clearly proceeded. The origin of this property change of the cis chromophore could be attributed to the photochemical formation of iodine atoms, capable to lead to a radicalic intermediate, when the free rotation is possible.

By reirradiation of the chromophore polyurethane films exposed to iodine vapors, the isomerization trans to cis takes place with a slower rate and finally a photobleaching effect was evidenced. Further experiments on these colored polymers with specific ionomeric architecture, useful in urethane coatings, are in progress in our laboratory.

\section{CONCLUSION}

We have attempted to extend our earlier syntheses of chromophoric polyurethane cationomers by chemical incorporation of aminoazobenzene units in the polymer chains beside quaternary groups. The photochemical induced changes achieved with a high pressure $\mathrm{Hg}$ lamp, evidenced photochromic properties only in dilute solutions. Compared to azo cationomers with chromophore bond to quaternary structure, the presence of azoaromatic groups in non-ionic fragment of hard segment indicated a sufficient mobility to ensure easily the reversibility of this photoprocess. In thin polymeric films, the trans-cis isomerization can be photochemically induced but to a lower level than in the solution, followed by a photobleaching effect at high irradiation times. The adding of some sensitizers namely benzophenone or nitropolyurethane has a negligible effect on the photobehavior of polyurethane films. By the treatment of UV irradiated films with iodine vapors, the cis to trans isomerization was also evidenced. 


\section{REFERENCES}

1. C. D. Eisenbach, Polym. Prepr., Am. Chem. Soc., Div. Polym. Chem., 21, 309 (1980).

2. Y. Onouchi, S. Inagaki, and J. Furukawa, Cell. Polym., 15, 30 (1996).

3. G. Mignani, R. Meyrueix, and C. Prud'homme, FR Patent 2650 287 (1991).

4. O. Watanabe, M. Tsuchimori, and A. Okada, J. Mater. Sci., 6, 1487 (1996).

5. M. Chen, L. R. Dalton, L. P. Yu, Y. Q. Shi, and W. M. Steier, Macromolecules, 25, 4032 (1992).

6. O. Nuyken, J. Stebani, and A. Long, Angew. Makromol. Chem., 226, 143 (1995).

7. C. S. P. Sung, L. Lamarre, and M. K. Tse, Macromolecules, 12, 666 (1979).

8. L. Lamarre and C. S. P. Sung, Macromolecules, 16, 1729 (1983).

9. X. Yu, B. P. Grady, R. S. Reiner, and S. L. Cooper, J. Appl.
Polym. Sci., 47, 1673( 1993)

10. D. Dieterich, Prog. Org. Coat., 9, 281 (1981).

11. H. Reiff and D. Dieterich, 'Urethane Based Ionomer Dispersions,' in "Ionomers," M. R. Tant, K. A. Mauritz, and G. L. Wilkes, Ed., Blakie, London, 1997, pp $444-476$.

12. E. C. Buruiană, T. Buruiană, A. Airinei, and G. Robilă, Angew. Makromol. Chem., 206, 87 (1993).

13. T. Buruiană, A. Airinei, E. C. Buruiană, and G. Robilă, $J$. Macromol. Sci., Pure Appl. Chem., A32, 1397 (1995).

14. T. Buruiană, A. Airinei, E. C. Buruiană, and G. Robilă, J. Polym. Mater. 11, 95 (1994)

15. T. Buruiană, A. Airinei, E. C. Buruiană, and G. Robilă, Angew. Makromol. Chem., 226, 205 (1995).

16. T. Buruiană, A. Airinei, E. C. Buruiană, and I. Bestiuc, Angew. Makromol. Chem.. 258, 39 (1998).

17. I. Beștiuc, A. Caraculacu, S. Idriceanu, and T. Buruiană, RO Patent 104788 (1994).

18. I. Mita, K. Horie, R. Hirano, Macromolecules, 20, 2241 (1989). 